\title{
Language policy and orthographic harmonization across linguistic, ethnic and national boundaries in Southern Africa
}

\author{
Felix Banda
}

\begin{abstract}
Drawing on online and daily newspapers, speakers' language and writing practices, official government documents and prescribed spelling systems in Southern Africa, the paper explores the challenges and possibilities of orthographic reforms allowing for mobility across language clusters, ethnicity, regional and national borders. I argue that this entails a different theorisation of language, and for orthographies that account for the translocations and diasporic nature of late modern African identities and lifestyles. I suggest an ideological shift from prescriptivism to practice-orientated approaches to harmonisation in which orthographies are based on descriptions of observable writing practices in the mobile linguistic universe. The argument for orthographic reforms is counterbalanced with an expose on current language policies which appear designed for an increasing rare monoglot 'standard' speaker, who speaks only a 'tribal' language. The implications of the philosophical challenges this poses for linguists, language planners and policy makers are thereafter discussed.
\end{abstract}

\section{Background}

The aim of this paper is to evaluate some of the work that has been done on the harmonisation of orthographical conventions of African languages, with a focus on Bantu languages spoken in Southern Africa. Specific examples are drawn mainly from South Africa, Zambia, Malawi, Namibia and Zimbabwe. However, where appropriate, illustrations are also drawn from other countries in Southern Africa.

The paper's conceptualisation is informed by recent poststructuralist thinking in which speakers' spaces of interaction and use of linguistic resources are not bounded by rigid boundaries or inflexible hegemonic systems (Pennycook 2010; Heller 2007). In this conceptualisation, the notion of multilingualism and the relationship between language and identity is different from the traditional one built around the idea of linguistic distinctness (Heller 2007), and in which the world is seen as "a neat patchwork of separate [ethnic], monolingual, geographical areas almost exclusively populated by monolingual speakers" (De Schutter 2007, p. 3). Language is seen as social practice operating across ethnic, cultural, geographical, etc. boundaries, and across semiotic artifacts (spoken modes of semiosis, books, media, music, internet, etc.) as well as spaces (classrooms, homes, church/mosque, playgrounds, etc.) in different ways (Heller 2007; Stroud 2007; Banda 2009). 


\section{Harmonisation of Bantu language orthographies}

This writer has been involved in the most recent work on harmonisation of orthographic conventions of African languages, which started in 1998 under the auspices of the Centre for Advanced Studies of African Societies (CASAS) based in Cape Town. Although originally conceptualised around language clusters, in part inspired by Greenberg's (1966) language families and Guthrie's (1967) work on Bantu languages, it became clear that there was need to look beyond languages and clusters as autonomous systems, to language as social practice. This entailed moving away from looking at communities as homogenous, static and rural based, to heterogeneous, urbanising and mobile. Of particular interest was the fact Greenberg and Guthrie had determined that Bantu languages had similar morpho-syntax and vowel and consonant sounds. It was when it came to writing that major differences began to occur even where the words were pronounced the same across languages. Thus, in devising the seminal $A$ unified standard orthography for South- Central African languages [henceforth South-Central Orthography] (Banda et al. 2008), it became evident it would be futile and duplicative to look at Bantu languages as autonomous systems belonging to equally autonomous language clusters. One of the defining questions was: what and how are social actions and activities of people manifested linguistically in people's everyday life? This effectively shifted the focus from mutual intelligibility of Bantu languages and language use, to observed language practices in different contexts, which Pennycook (2010, p. 9) describes as a "move away from attempts to capture language as a system, and instead to investigate the doing of language as social activity, regulated as much by social contexts as by underlying systems".

We were mindful that how people wrote was dependent on affordances readily available. Considering modern technology, most electronic keyboards have similar standard letters which act as a control mechanism for 'normality'. The letters are more or less predictable, and it becomes difficult to write a script with letters that are not readily available on keyboards as one either has to call special characters by using a combination of other letters and function keys, or create own characters which can take time and require computer programming skills. Further, it was determined that orthographies should be delinked from ethnic groups, dialects, languages, communities, regions and nations/countries. In this regard, it was resolved that as much as possible the orthographies should not be named after specific languages and countries. Thus, the South-Central Orthography and others abstracted from it are translinguistic and transnational, with authors coming from different linguistic, regional and national backgrounds (see for example the listed co-authors in Banda et al. 2008; Wakumelo-Nkolola et al. 2008).

Language standardisation is defined as the process by which a language is codified, which involves the development of grammars, spelling books, dictionaries, and so on (Wardhaugh 2006). The standard language is often used for writing books, newspapers, and in official government documents and high functions, such as formal meetings, and is often used alongside what are considered low varieties. Weber and Horner (2012, p. 17) are critical of what they call the standard language ideology which is based on the assumption that languages are internally homogenous entities with strict 
borders between them, a belief which totally ignores the constant blending and borrowing between different languages by ordinary people, as is the norm in multilingual societies. The harmonisation of orthographies that I have been involved, on the other hand has involved speakers of the language(s) and other stakeholder, capturing the sound inventories of the languages or linguistic repertoire of speakers, and then determining how best to represent the sounds in writing. As noted elsewhere, it is not possible to have entire communities in one venue to agree on a particular writing system. Isolating the sounds of varieties of languages concerned means the extended linguistic repertoire becomes the resource on which speakers draw their writing system. Most Bantu languages have a basic five vowel system, but the number of consonants may differ. Moreover, since the languages tend to be agglutinative (a term I define elsewhere), the morphosyntactic structuring of the languages, which gives a clue to how the languages should be written, are similar. Technological developments, especially use of software and electronic keyboards, are also helping levelling off language boundaries, as how and what people write is often determined by the letters and affordances on the gadgets.

Although the harmonisation process as described above tries to avoid imposing an orthography by involving speakers in the design of the writing system, it could still be argued that it still involves elements of standardisation in apportioning particular letters to particular sounds. Still, the process of harmonisation as described here limits the impact of the hegemonic ideology which allows for certain language varieties to be chosen for standardisation simply because of the socio- political power of their users (Fredericks 2014).

Ndhlovu (2013, p. 29) captures the distinction between harmonisation and standardisation thus: "While standardisation...elides language variation and diversity through its pursuit of uniformity, harmonisation seeks to harness the incidence of mutual intelligibility found among structurally and genetically-related languages to enhance cross-linguistic and inter-cultural communication". I want to add that harmonisation is also about taking advantage of the 'natural' harmonisation (Chisanga 2004; Banda 2008) resulting from the integrated multilingual/linguistic repertoire of the rapidly urbanising Africans and the 'normalising' affordances of computerised keyboards in which different speech communities share font-types.

It has to be noted that attempts to harmonise African languages' writing systems are not exactly recent. There was orthographic work by the International African Institute (IAI), which in 1927 came up with the first edition of the African alphabet and the expanded second edition was released in 1930 (Chanda 2002). Then there was work in 1937 by the Inter-University Committee for African Studies (IUCAS), comprising prominent Bantuists, GP Lestrade, CM Doke, JA Englebrecht and VN van Warmelo, who met and decided on how to spell Bantu languages and 'tribes' in English (Banda 2002). In 1996, there was the Cross-Border Language Workshop held at Okahandja, Namibia attended by eminent African linguists and well known European experts on African languages (Chanda 2002). The orthographies to come out of these endeavours tended to be dependent on linguistic theory and/or the missionary's or linguist own intuitions. 
In the technologically driven writing of modern Africa, orthographic designs need to consider different practices by ordinary people online and other platforms. Because of constant cultural flows between rural and urban areas of Africa, 'ordinary people' refers to both rural and urban dwellers, the literate and the not so literate. The linguistic and cultural borders between the urban and rural people have been shown to be porous as Africans keep crossing these borders in their everyday interactions (see Mc Laughlin 2009 for West Africa; Higgins 2009 for East Africa and Makoni et al. 2010, Makoni and Mashiri 2007 and Banda and Bellonojengele 2010 for Southern Africa). Banda (2009) argues that patterns of trans-'tribal' commerce and trade, and the close proximity and density of related and not-so- related languages in many parts of Africa suggest that forms of multilingualism have been the norm in Africa for centuries, even before colonialism. Colonial languages such as English and French merely added another dimension to the complex linguistic mix. Commenting on hybridity in speech patterns, Lutz and Kula (2008, p. 18) contend that "the present-day language situation in Zambia is not so much a product of the colonial era, but is instead based on a dynamic system of multilingualism which has developed over several centuries. A number of the languages which play a part in the contemporary set-up have been spoken-in older forms-in the area since the middle of the last millennium". Before Europeans came to Southern Africa speakers of isiZulu, isiXhosa and seSotho had incorporated click sounds into their speech forms as a result of contact with Khoisan communities. We know that isiZulu, isiXhosa and seSotho are Bantu languages and there are no click sounds in protoBantu (cf. Miti 2006; Guthrie 1967). This means, for example, the voiceless velar aspirated click sound in the name of the language isiXhosa [isi $\mid \mathrm{k}^{\mathrm{h}} \mathrm{osa}$ ] is derived from Khoisan languages, showcasing the convergence and malleability of linguistic forms.

I need to point out from the outset that conflicting interests and the number of stakeholders surrounding orthographies means that writing systems whether harmonised or not are sites of contestation. The following is a summary of some of the successes of the CASAS harmonisation project. This is followed by a more extended discussion of the challenges and contestations around cross-linguistic and cross-border harmonisation of writing systems.

\section{Summary of successes}

The successes can be summarised in note form as follows:

- Has revitalized African linguistic research as a distinct and viable area of academic engagement.

- Raised awareness that African languages are an important factor for inclusive education and socio-economic development in Africa.

- Has brought about cross-linguistic and transnational collaboration among academics.

- Has brought about cross-linguistic and transnational collaboration among school book writers and curriculum specialists.

- Readers, dictionaries and monographs have been written and published.

- CASAS has used linguists and experts in various fields as consultants and resource persons, who have provided refresher courses to curriculum specialists and book writers in Southern, Eastern and West Africa.

\section{http://repository.uwc.ac.za}


- In Zambia, Zimbabwe and Uganda primers and dictionaries in African languages have been written and published, in conjunction with the countries' curriculum development centres.

- The Ministry of Education in Angola approached CASAS in 2013 to help devise an orthography for Khoisan languages in the country.

- Tonga chiefs, writers and teachers in Zimbabwe asked CASAS to set meetings with counterparts in Zambia, including those working at the Curriculum Development Centre in Lusaka, charged with ensuring quality control in chiTonga schoolbooks for Zambian schools. A chiTonga cross-border orthography, abstracted from the SouthCentral Orthography was agreed upon, and the Ministry of education in Zimbabwe have since ordered primers from a Zambian publishing house that attended the meetings.

- At the request of the National Institute for Educational Development (NIED), a department of Ministry of Education, in Namibia, which is charged with curriculum development, CASAS convened a meeting on 19 November 2013 of language specialists and stakeholders at which harmonisation of Namibian Bantu and Khoisan languages was discussed. Of interest at this workshop was that a Namibian siLozi specialist said that her primary school learners found it much easier in terms of reading and writing using the CASAS cross-border (Zambia-Namibia) orthography, than the old Namibian one.

Although the above illustrate what can be achieved through sharing linguistic expertise and orthographies across borders, I should point out from the outset that there have been strong resistance to change and to modernise African writing systems from some academics and stakeholders who felt the old ways were good enough. For instance, at a recent meeting for primary school teachers in Kampala, Uganda to discuss A unified orthography of Eastern Interlacustrine Bantu Languages: Luganda, Lumasaaba, Lusaamya and Lusoga (CASAS Monograph 68), some delegates strongly objected to the suggestion to replace the prescribed symbol $<\mathrm{y}>$ used for the velar nasal, with the <ng'> [(Nankindu 2013).

Arguments that the $<$ ng $>$ is more readily accessible on new technology keyboards and that it is already more widely used than the prescribed symbol, and that the former symbol has little currency among the younger generation and large amounts of written material outside the classroom, had very little impact as they felt this would 'destroy [our] language' and 'culture elements' (Nankindu 2013: 2). Below I summarise some of the challenges and contestations to reform and harmonisation of orthographic conventions of related languages.

\section{Summary of challenges}

There are a number of challenges and contestations surrounding the orthography harmonisation project.

\section{Conflicting national language policies}

Different countries have different policies on the languages of education. At several workshops organised by CASAS for subject specialists, writers and schoolbook publishers in Zambia, Malawi and Mozambique for ciNyanja/ciCewa, participants

$$
\text { http://repository.uwc.ac.za }
$$


expressed the wish to work closely but it was observed that this arrangement requires the blessing of political figures, which has proved difficult to come by. In January 2014, the Zambian and Malawian governments made different and contradictory language education policy statements: while the Zambian government announced that they would drop English and use Zambian languages as media of instruction from grade 1, the Malawian government announced that they would drop ciCewa and other Malawian languages and instead start using English as the medium of instruction from grade 1. These policy changes caught the public, linguists and teachers in both countries by surprise as the schools were not prepared in terms retraining of teachers and teaching materials in a new language of education. In Zambia, although teachers were expected to teach in Zambian languages, the Lusaka Times online newspaper reported that by the end of March 2014, the government had still not printed teaching material or trained teachers to teach in Zambian languages (see "Teaching Materials in a New Curriculum Coming Soon." Lusaka Times, 20 March 2014. http://www.lusakatimes.com/2014/03/20/ teaching-materials-new-curriculumcoming-soon-ngoma/. Accessed on 22 March 2014). It is clear that the two countries had not consulted on experiences regarding use of English (Zambia) and use of African languages (Malawi) for initial literacy development.

\section{Problem of overcoming sentimental value}

Banda (2008) observes that the anomalies and inconsistencies, albeit found in the written forms of African languages, have acquired socio-cultural, political and sentimental value. They are often cited by the educated African elite as distinguishing factors between what in reality (at least in the spoken form) is the same language. The various orthographic conventions operating in the Sotho-Tswana language group are illustrative. Although Bantu languages are agglutinative in nature, the prescribed writing systems of Sotho-Tswana languages range from almost entirely disjunctive in Sepedi (Northern Sotho) to more or less a combination of the two in Setswana. By agglutinative is meant the fact that majority of words and sentences are formed by combining several morphemes together (Miti 2006). As will be shown in due course, cultural reasons are brought in to override theoretical linguistic and practical reasons, and to argue for a disjunctive writing system. Below I use examples from Northern and Southern Sotho, both written disjunctively, and ciNyanja and chiShona which are written conjunctively to illustrate possible literacy problems with writing bound morphemes as if they are independent words or free morphemes. I have included morpheme breaks (-) in the transcription to indicate morpheme boundaries and hence bound morphemes.

\begin{tabular}{|c|c|c|}
\hline 1. Ke ngwadile & [ke-ngwadil-e] & 'I wrote' (Northern Sotho) \\
\hline 2. Kea ngola & [ke-a-ngol-a] & 'I write' (Southern Sotho) \\
\hline 3. Ke tla u ngolisa & [ke-tla-u-ngol-is-a] & 'I will cause someone to write' (Southern Sotho) \\
\hline 4. Ndilemba & [nd-i-lemb-a] & 'I write' (ciNyanja) \\
\hline 5. Ndalemba & [nd-a-lemb-a] & 'I have written' (ciNyanja) \\
\hline 6. Ndidzalembetsa & [nd-i-dza-lemb-ets-a] & 'I will cause someone to write' (Causative) (ciNyanja) \\
\hline 7. Ndidzalembela & [nd-i-dza-lemb-el-a] & 'I will write for someone' (Applicative) (ciNyanja) \\
\hline
\end{tabular}


The roots -lemb-, -ngwadil- and -ngol- represent 'write' to which the supporting morphemes or affixes are attached. The affixes -ets-/-is-, and -el- represent the causative and the applicative respectively. Future time is indicated by the affixes - dzaand -tla-. These are bound morphemes and not words that can stand on their own. The morphemes ke-, nd-, and t- are not words in the sense of 'I' or 'we.' Similarly, the modals 'will' and 'have' do not exist as words in these languages. Their sense is carried by tone and/or bound morphemes in the agglutinated forms. In the example below, in contrast to chiShona, in Southern Sotho, bound morphemes 'they', 'shall', 'are', and 'him' are written as words or free morphemes, yet their meaning is carried by the entire agglutinated form rather than in isolation.

\begin{tabular}{lll}
\hline $\begin{array}{l}\text { 8. Vachandomuona } \\
\text { 9. Vanotamba }\end{array}$ & $\begin{array}{l}\text { [va-chando-mu-on-a] } \\
\text { [va-no-tamb-a] }\end{array}$ & $\begin{array}{l}\text { 'They shall see him' chiShona } \\
\text { 10. Vana vanotamba }\end{array}$ \\
$\begin{array}{l}\text { [Vana va-no-tamb-a] } \\
\text { 11. Ba bapala }\end{array}$ & 'Children are playing' chiShona \\
$\begin{array}{l}\text { 12. Bana babapala } \\
\text { 13. Ke mu bone }\end{array}$ & 'They are playing' Southern Sotho \\
\hline
\end{tabular}

In sentences 8 and 13, the object morpheme -mu- stands for 'him/her', only when bound. For instance, if one was to ask in chiShona or Southern Sotho 'Who did they see?' it would not make sense to say '-mu-'as the morpheme on its own is meaningless (Miti, personal communication). Note also that if the morpheme va- or ba- was the same as the English 'they' then sentence number 12 would be 'Children they are playing' which would be as awkward if not ungrammatical as the English version. Similarly, to the question who is playing one cannot say 'va-' or 'ba-' to mean 'him/her,' 'he/she' or 'them' or 'they' as in English as the Sotho forms are bound and their meanings are realised in agglutination.

It may be argued from the above examples that ciNyanja and chiShona children have fewer rules to deal with in terms of learning to write compared to Northern Sotho and Southern Sotho. Indeed, Msimang (1998) suggests it is easier for a child to learn the morphosyntactic rules of isizulu conjunctive writing, as they are fewer rules to master, than a Sotho child who has to learn a lot of rules. In South Africa, the National Education Evaluation and Development Unit (NEEDU 2012) of the Ministry of Education in its national report titled The State of Literacy Teaching and Learning in the Foundation Phase found significant differences between spoken African languages and their written forms. The disjunctive writing system in Sepedi (Northern Sotho) and Setswana are particularly singled out as being problematic for early literacy development.

Northern and Southern Sotho have a high degree of mutual intelligibility. However, the differences found in the orthographies are seen as part of each of the two communities' cultural heritage. For example, for the voiceless fricative palatal sound, Southern Sotho uses the diagraphs [sh] while Northern Sotho uses the phonetic symbol [̌̃ ]; and for the unaspirated and aspirated voiceless affricate sounds the diagraphs [tj] and [tjh] are used in Southern Sotho, while in Northern Sotho they are rendered as [tš ] and [tš h]. Machobane and Mokitimi (1998) report that respondents from Lesotho (Southern 
Sotho) rejected a proposed simplified and 'modernised' orthography on account that the one they were using was part of Lesotho (national) identity and that the proposed one was similar to one in use in South Africa, thus it was 'South African'.

\section{Contested priorities}

Governments and NGOs in Southern Africa have their priorities set on health issues such as HIV/AIDS and poverty alleviation, and have paid little to efforts to reform and develop effective orthographies.

\section{The church and other stake-holders}

The stake-holders range from education and the various government ministries including health, legal, culture and national development, to chiefs who pride themselves as custodians of culture and language. It is not possible to have all stake-holders represented at workshops, those left out cry foul. This has implications for the legitimacy of the translingual/transnational orthographies or material produced.

The missionaries and the church still have considerable influence in Africa. To some the idea of 'modifying' the written language is sacrilegious as it is tantamount to fiddling with the Holy Book. During the harmonisation work cross Africa, representatives from the various churches and publishers of missionary works were often invited to attend the harmonisation workshops. In almost all cases they never attended the workshops.

\section{Disagreements among linguists and language specialists}

Although in most cases consensus was reached, there was usually disagreement on a number of theoretical and practical issues on what the best writing practice should be. For instance, for ciYao, the Malawi group felt it was unnecessary to double long vowels, while the Mozambican group felt it was absolutely necessary to do so. In ciNyanja the liquid $<\mathrm{l}>$, and $<\mathrm{r}\rangle$ found in 'borrowed' words are in free variation, but the tendency is towards the $<\mathrm{l}>$. However, in the official written form of the language there are more than ten rules prescribed for when to write either $\langle\mathrm{l}>$ or $<\mathrm{r}\rangle$. However, the suggestion to scrap the rules as has been done in South-Central Orthography to bring the written form in line with how the language is spoken was contested by some writers and ciNyanja subject specialists in Zambia.

In the next section, I draw mostly on the official orthographies (MoE 1977) of the seven Zambian languages and the language practices as seen on websites, newspapers and official government documents to show how the official orthographic conventions are divorced from writing practices in place.

\section{Hybrid language practices in urbanising Africa}

Language planning and policy in Africa has not moved in line with current language practices (Makoni et al. 2010). It has not accounted for massive migrations and urbanisation in Africa, and the constant crossing of the rural-urban spaces by both rural and urban people due to improvements in air and road networks. Advances in mobile technology and proliferation of social media and cyber networks mean one can be 'home' and diasporic at the same time. Banda and Bellonojengele (2010) argue that it is 
becoming difficult to separate urban and rural, modern and traditional lifestyles and language practices as these tend to emerge as integrated in social contexts.

I shall argue that the language practices illustrated below suggest hybrid language practice is the natural linguistic dispensation for late modern Africans; while the monoglot 'standard' forms are relegated mostly to the classroom. There is no place for strict monoglotism as even in rural areas languages such as French and English are taught in the classroom alongside African languages at some stage. Children are constantly exposed to hybrid forms through various media. Consider the following report on the rural districts of Ehlanzeni and Francis Baard in South Africa in which teachers expressed concern that monoglot terms used in teaching mathematics in siSwati were hindering learning:

Several teachers interviewed in the Ehlanzeni District complained about the difficulties they experienced in teaching mathematics in siSwati. Learners were exposed to the English names for shapes, numbers and colours at home and in the community, and were unfamiliar with the complex siSwati terminology. The terminology used, and the number names in siSwati, were described as 'difficult' and 'confusing.' (NEEDU 2012, p. 35).

Although geographically the district is in a siSwati speaking area, the learners have been exposed to shapes, numbers and colours in English. In using official siSwati terminology, the teachers can be said to follow the language education policy, but in the process use terminology that is foreign to the learners. Thus, teachers find that the monoglot terminology in siSwati is counterproductive in as far as literacy development is concerned.

Similarly, for seTswana, the NEEDU (2012) report noted that whereas learners were familiar with the hybrid term ecircle ('circle'), the (seTswana) monoglot term sekeletsa was used in the instruction which made the question incomprehensible to the learners. The report concluded that effective teaching in mathematics can only be achieved "across the country" if hybrid, that is, "Africanised English terms [are] used, since [they] are more widely known by teachers, parents and children than the more contrived ... 'official' terms. Some schools unofficially adopted this as their chosen solution to the problem" (NEEDU 2012, p. 37). The report thereafter suggests the need for restandardisation of South African languages to take into account how the languages are currently being spoken, and the multilingual nature of communities, including rural ones.

Focusing on iciBemba and ciNyanja language practices in Lusaka, Chisanga (2004) describes the 'natural' harmonisation of Zambian languages in which iciBemba, ciNyanja, English and other languages are integrated into an extended linguistic repertoire. This integration is not seen only in speech forms but also in the crystallisation in use of a common or similar spelling system as evident in online chat rooms and other internetbased discourses as well as national newspapers. Thus, even though in education and officially, seven different orthographies are prescribed for the seven regional Zambian languages, in practice as shown in the website writings and daily newspapers, speakers write the same way. In the official Zambian orthographies (MoE 1977) three graphemes are prescribed for the velar nasal sound for various languages. These are $\langle\mathrm{y}\rangle$ for 
iciBemba and chiTonga; <ñ $>$ for kiKaonde, Lunda and siLozi and <ng'> for ciNyanja. However, as demonstrated below the language practice on the websites, the media and even in official government documents, is to use <ng'>. It is also noteworthy that for chiTonga, the MoE (1977) orthography suggests the $<\mathrm{cc}>$ be used for the voiceless postalveolar affricate. However, in practice as is also shown below with regard to chanza, a chiTonga word meaning 'hand,' the diagraphs $<\mathrm{ch}>$ are preferred. Moreover, if the MoE (1977) orthography for chiTonga was followed, the name of the language should be written as CciTonga.

Let us consider the following extracts from a website:

Context The four interactants are discussing an article in the Zambian Watchdog an online newspaper which suggested that Rupiah Banda of the Movement for Multiparty Democracy (MMD) who had just lost Presidential elections in Zambia to Michael Sata's Patriotic Front (PF) could face corruption charges. The United Party for National Development (UPND) was in an alliance with Sata's PF against Banda's MMD until a few months before the elections when they went their separate ways. Tandiwe (also written as Thandiwe) is Rupiah Banda's wife.

1. Benny: Ba UPND chanza chinajubika pa [You UPND people you had your fingers burned on...(chiTonga/urban ciNyanja)] ['chanza' a Tonga word refers to the UPND political symbol of a hand pointing in the forward direction] $20^{\text {th }}$ September, you can't have an underfive business boy for President. Soseni nomba ba UPND ati [You speak, now you UPND do you still think that...(Nyanja/Bemba)]you are popular than PF Wynter was correct when he said the PF did not need the UPND to win an election. So mulimbe ba mambala [...you must just persevere, you crooks! (English/Nyanja/urban Nyanja)].

2. Dr. Mackson: tandiwe ali bwanji amalume kufarm,very soon twalabakaka to acount what he stole to us zambians incuding u...he is going to jail zoona [Thandiwe, how is uncle [Rupiah Banda] at the farm, very soon we shall lock him up...believe me. (English/ciNyanja/iciBemba)].

3. Mutale: Dr. Mackson twafuma nankwe ukutali.manje iwe ukamba bwa. Ndi pamene twa tiliga [Dr. Mackson we have a long way with him. What are you talking about? (This is when we have woken up in the sense of becoming aware of something, a term taken from the English word "trigger") (English/iciBemba/ isiZulu/chiTonga/Urban ciNyanja/Standard ciNyanja)].

4. Membe says: yakosa inkani bane ba jelabo, no more illeagl copper business [Things are have gone awry for you jelabos (copper thieves)...(iciBemba/urban iciBemba/ciNsenga/ciNyanja/English)] (This is a reference to the stance that Sata has taken against corruption. In a way it is a warning to the copper thieves that took advantage of Rupiah Banda's weak stance on corruption and fraud).

I have labelled the hybrid forms with the source languages for convenience, as speakers do not distinguish the morphemes as coming from different languages. In any case, the meanings of the sentences do not lie with the source languages but as an integrated linguistic form itself. For these speakers, the 'conversation' above constitutes the normal speech form. 
In the above example, the rural and urban forms of Zambian languages and formal and non-formal English constitute the normal repertoire. The first contribution is a hybrid form combining rural and urban iciBemba, chiTonga, ciNyanja and English. The second contribution starts with an iciBemba version of the name Thandiwe (that is, written without an ' $h$ '), but followed by 'standard' ciNyanja, followed by 'kufarm' a hybrid word combining the Bantu locative prefix $k u$ with the word farm (that is 'at the farm'), interspaced with the English, very soon and the 'standard' iciBemba phrase twalabakaka ('We shall lock him up'). The phrase zoona though originally from ciNyanja to mean 'true' or 'truly' has become part of iciBemba speakers' vocabulary. This is interesting because the MoE (1977) iciBemba orthography suggests the sound /z/does not exist in the language. The third mixes standard and urban ciNyanja, isiZulu, chiTonga and iciBemba. The fourth example starts in ciNsenga (Yakosa = 'It's hard') and followed by a word made up of iciBemba and ciNyanja affixes (I-nkani = 'News'). The 'standard' word for news in iciBemba is ilyashi, while in ciNyanja it is nkhani. The phrase yakosa inkani means 'Things are bad.' To show how bad things will be for Former President Banda, the writer combines the iciBemba prefix i-with the ciNyanja stem --nkhani, only in this case the writer drops the aspiration marker [h] to come up with the non-aspirated sound typical of a rural iciBemba monoglot speaker. The term jelabo is a recent urban neologism referring to syndicates that steal copper bars or products from the copper mines on the Copperbelt Province of Zambia and sell them illegally as scrap metal in Zambia or abroad.

The use of amalgams and hybrid language is not a rarity in the daily newspapers in Southern Africa. Newspapers are merely taking advantage of the language practices in place to reach a wider audience and to fine-tune meanings, evaluations and messages. Below is an extract from the Post Newspaper, an 'English' Zambian daily paper, in which English and iciBemba have been amalgamated into a linguistic repertoire.

\section{Fr Chilinda asks Sata to forgive Rupiah}

By Thomas Nsama and Ernest Chanda

President Michael Sata yesterday disagreed with St. Ignatius assistant parish priest, Fr Charles Chilinda when the latter asked him to forgive his predecessor Rupiah Banda for the wrongs he may have committed during his reign...

"And I hope that President Sata is listening, and I ask President Sata to set a precedent by forgiving his predecessor despite the differences they had", Fr Chilinda said. "Kaunda balisa munyankula, Chiluba nao aisa nyankula Kaunda, Mwanawasa nao aisa nyankula Chiluba. (Kaunda was defeated in an election, then Chiluba persecuted Kaunda, Mwanawasa also persecuted Chiluba); the only person who was not persecuted was Mwanawasa who was 'saved' by death". Fr Chilinda said the trend had been that now that elections were over, it was not time to fix opponents...Then Fr Chilinda walked towards President Sata who then said to the congregation that: "What Fr Chilinda is saying is that we should not fight corruption. Nomba nga baliba ninshi kubelela? (If people stole, should they be forgiven?) Ine nalilandile ati (I had said that) the governing of this country will be based on the Ten Commandments", President Sata said, amidst ululations and applauds from the congregants. [My italics]

\section{http://repository.uwc.ac.za}


Also of interest here is that although iciBemba is used, the spelling system used is contrary to the one officially sanctioned by government, that is, the MoE (1977) document. In the extract, all the vowels are rendered as single vowels, without doubling of long vowels as is prescribed in the iciBemba orthography. From a linguist's perspective the short and long vowels constitute minimal pairs in iciBemba, but do not appear to cause comprehension problems as readers are able to decipher the meanings from the contexts of use. The MoE (1977) document suggests the iciBemba words baliba, balisa and kubelela should be written, respectively, as baliiba, baliisa and kubeelela. It is practical to use short vowels for ease of reading and because speakers easily predict long vowels from the contexts.

It is also interesting that the exchange is taking place in church, a 'formal' domain, in which 'standard' language is expected to be in use. From a monolingual perspective, the seamlessness in which iciBemba and English is blended is remarkable, but this is a normal happenstance in the integrated urban discourses of Africa. The sermon itself, the accompanying songs sung in different languages and the linguistic hybridity of the exchange between Sata and the priest defy the arguments that domains determine the kind of language used. I want to argue that the idea that certain languages or forms are implicated in, or that they are a function of socially structured and organised domains of language use, is increasingly becoming difficult to prove in the urban settings of Africa (Banda and Bellonojengele 2010). This is because languages or forms of languages emerge as integrated amalgams across contexts and domains. The communicative effect in the above extract is achieved through the English/iciBemba amalgam rather than linguistics of difference. This is the way Sata speaks even at official functions. He may address foreigners in English on special occasions, but that is not an everyday occurrence. As implied above even official government documents show the disjuncture between the prescribed official spelling and what obtains in practice. In the official iciBemba draft Zambian Constitution (Zambian Government 2012), the velar nasal is written as <ng'> throughout. For instance, the word for 'house' is written as ing'anda and not iyanda as prescribed in the official orthography. The language practice in newspapers, magazines and official government documents such as the passport, is to avoid phonetic symbols such as $\mathrm{n}$ and $\mathrm{n}^{\sim}$ as is prescribed in iciBemba and other languages, respectively. These symbols are only found in the bible and schoolbooks prepared by the government's Curriculum Development Centre (charged by the Zambian government with the responsibility of ensuring quality control of material used in primary and secondary schools). Thus, the language and literacy practices that children are familiar with and bring to school are at odds with language prescriptions and official government orthographic demands.

Clearly, the writing practices exhibited above are shown to be similar across mode, linguistic and ethnic background of the writers. The transnational and diasporic nature of modern living coupled with technological developments which have made possible borderless social networking, have engendered the kinds of interactions and communication that celebrate commonalities rather than divergence in language practices in late modern Africa. This calls for versatile modern and hybrid orthographic designs that are not overly prescriptive but account for writing practice in place, which as 
shown above are not restricted to a particular language, ethnic and regional grouping or nationality.

\section{Implications for language planning and policy}

Given the similarities in language practices as described above, one would think it would be easy to plan across languages and national boundaries. But this is not necessarily the case, as for example, written differences are often celebrated as part of a people's unique cultural even ethnic heritage. For instance, Machobane and Mokitimi (1998) and Matlosa et al. (2003) found that political and perceived cultural differences prevented seSotho, seTswana and sePedi speakers, and seSotho speakers in Lesotho and South Africa to use the same spelling system.

Similarly, Banda (2008) argues that whereas in Zambia the language is called ciNyanja, in Malawi it is called ciCewa. There are differences in this same language in the manner the aspirated voiceless palatal sound [th] is written. It is written as [tch] in Malawi, but as [ch] in Zambia and Mozambique (Banda, 2008). In Malawi, the unaspirated voiceless palatal sound $/ \mathrm{t}^{\mathrm{h}} /$ is written as [ch] or [c], but as [c] in Zambia and Mozambique. Thus, despite the very large numbers of ciNyanja speakers, the inconsistencies in the written form of the language, make it difficult for the three countries to share education material. Coupled with all these issues is the fact that the language planning and policies are based on a rural monoglot 'standard' speaker whose speech forms are oftentimes based on an obscure dialect. Thus, the language used by teachers and learners is not necessary the one spoken in the communities or one readily understood by learners. There is need to decenter the 'standard' African language as the main means of interaction in classroom contexts. This means recognising integrated hybrid forms of speech as legitimate language for various social intercourses including in classroom contexts (cf. Makoni et al. 2010).

Because of similarities in Bantu languages, and the hybridity in speech behaviours of speakers, language planning and policy needs to be cross-regional, cross-linguistic and cross-national in nature. Similarly harmonisation of writing systems need not only take a cross-border perspective, but should also be seen as a natural consequence of shared human linguistic experiences. Thus, cross-border orthographic harmonisation needs to be a feature of language planning as a way to enlarge readership as well as to remove anomalies and unnecessary impediments to early literacy found in current orthographies. In this regard, Cooper (1996) argues that the purpose of language planning is to enhance political, scientific, education, economic, etc., development. In essence, he argues that the ultimate object of language planning is to enhance actorhood and agency in speakers. Current policies on language and orthographies in Southern Africa often do the opposite. Moreover, efforts to modernise African languages and related spelling systems through corpus planning are often thwarted as the point of reference for majority of language planning and policies in Southern Africa seems to be languages as were spoken in colonial and pre-colonial times. For instance, the definitive grammars of a large number of African languages were written before the 1940s. Zerbian and Krifka (2008, p. 2) note that although there are many linguistic materials on Swahili, Ashton (1944), "which also was designed as a textbook", is still the most comprehensive reference grammar. For Northern Sotho, Ziervogel et al. (1969) is said to be one of the two standard reference grammars. 
The phenomenon of using African languages as were spoken in the pre-colonial and colonial past as references to how they should be spoken in the new dispensation is pervasive. For instance, even though words such as mudala or 'old man/chap', dokota 'doctor' and 'Zambia' are part of iciBemba speakers' language practices, the voiced sounds /d/, /v/ and /z/ are described as not to exist in iciBemba in the MoE (1977) document. Most interesting is that the name of the Paramount Chief of the iciBemba language speaking people of Luapula Province in Zambia is Mwata Kazembe. If one follows the logic of the prescribed orthography, the subjects would be unable to write the name of their country and the name of their Chief as both have the voiced sound /z/. Modern iciBemba speakers have both voiced and voiceless consonants in the repertoire (cf. Chisanga 2004). Reducing their vocabulary to only voiceless consonant sounds as prescribed in the MoE (1977) orthography and other traditional grammar texts (Kashoki 2009) would deprive speakers of a large vocabulary and limit their capacity to communicate effectively and efficiently.

Outdated and overly prescriptive orthographies and language policies have had particular negative effect on terminology development, a branch of corpus planning. Corpus planning is designed to reform the phonology, lexicon, grammar and spelling of a language. Cooper (1996: 154) proposes renovation as the goal for corpus planning, which he defines as 'an effort to change an already developed code, whether in the name of efficiency, aesthetics, national or political ideology'. The amalgams and hybrid language practices in urbanising Africa show creative ways which corpus planners can follow to devise new terminology and aspects of grammar and writing. Copper (1996, p. 154) argues that corpus planning is embarked on by "elites and counterelites as a tool for acquisition and maintenance of power". In Southern Africa, corpus planning is a preserve of a few elites based at specialised language units at universities or government institutions, where they churn out terminology, which rarely gets into the main stream and if it does, it "baffles" and "confuses" the learner (cf. NEEDU 2012, p. 38). There is need for planners to learn from African learners who defy monoglot classroom norms to discuss complex ideas and theories using a hybrid of African languages and English (Banda 2010). They are more likely to make sense of the terminology they have created in contexts of learning, than using the terminology created in specialised language laboratories.

Orthography harmonisation as an aspect of corpus planning will have to take into account the affordances on standard keyboards and electronic devices which provide an already harmonised alphabet, as well as the linguistic hybridity arising from urbanisation and globalisation; all of which have the effect of blurring traditional linguistic, ethnic, regional and national boundaries. There is no reason why related languages such as isiZulu, siSwati, isiNdebele and isiXhosa should have different terminology development units (cf. Jokweni 2003). These units should be pooling their expertise and working together for the development of the Nguni languages and its speakers across regions and national borders. As Coulmas (2005, p. 200) notes, the problem with language planning currently is that it is based on the Western or European notion of 'language' with 'one clearly distinguished from the other'. Such perceptions of language mask the fact that the differences between the languages concerned are as a result of scholars deciding on 'choices in phonology, lexicon and grammar' rather than language practices in place. Over time such 'invented' linguistic differences (Makoni 1998a, b) are seen as natural 
differences, so that there "is no room for a linguistic landscape with overlapping, vague and unstable language identities where language/dialect issue is unresolved because it is irrelevant" (Coulmas 2005, p. 200). If there is anything we can learn from the discussion above, is that speakers perform multiple identities, with overlapping, indistinct and unstable language loyalties. Rapid urbanisation and mobility of Africans into the burgeoning modern cities and back into traditional lifestyles, has blurred boundaries between urban and rural lifestyles, which accounts for hybrid language practices becoming the norm rather than the exception. Yet language policies are still based on distinctive languages, with a homogenous monoglot community.

It is not surprising that a number of enlightened Western and non-Western academics including eminent African scholars (see Prah 1998; Djite 1990) have questioned the notion of language planning as handed down to Africa, and particularly, Western conceptualisation of language in Africa. What has particularly come under fire is the delineation of African languages based on ill-conceived Western notions of the sacrosanct nature of the 'standard' language. This has effectively reduced the number of readers of African languages in real terms. First, books are written with a rural monoglot speaker in mind. Second, as the readers have been divided into different regional or national language groups, each with its own writing system and, each with its own graphemic representation and rules for spelling, this further erodes the number of potential readers. However, careful language planning and cross-linguistic referencing would enable these languages to share a large amount of teaching and reading material, as well as readership.

\section{Conclusion}

One of the most enduring legacies of colonialism is the image of a happy African who has his/her roots in a tribe and traditional village, practising his/her own culture and traditional rituals, and using his/her own language. Furthering the notion of the Tower of Babel, the language he/she speaks is perceived to be incomprehensible to neighbouring communities, who have their own tongues. For unexplained reasons, in this conceptualisation, the language contact phenomena in which speakers of different languages tend to congregate in "areas of linguistic confluence" (Gough 1994, p. 11), does not seem to operate. My argument is that this notion of a 'cultured' traditional Africa is no longer tenable, as hybridity in identity performance and language practices are the norm. The missionaries take the blame, sometimes unnecessarily, for dividing Africans through their orthographies, while linguists such as Doke and Guthrie are honoured for doing the same thing, which is, caging languages into zones, which came to be seen as autonomous clusters. The linguistics of prescription, difference and autonomy of linguistic systems dominate language planning and policy documents, to the detriment of shared language practices and experiences. The shared linguistic system among Bantu languages, rapid urbanisation and the onset of technology and already 'harmonised' symbols and letters on keyboards means that there is already a shared writing system. Thus the linguist and language planners and policy makers do not have to prescribe, but to describe the writing systems in place.

This means the democratisation of multilingual African spaces to enable integrated hybridity identities to be exhibited through amalgams as legitimate social semiotics. This entails weaning African multilingualism from distortions resulting from the colonial

$$
\text { http://repository.uwc.ac.za }
$$


legacy and the pervasive monolingual prescriptions that underlie language policies in Southern Africa. There is need to be cognisant of the affordances by technology and the changes in the linguistic universe resulting from urbanisation, and the philosophical turn that these entail, in which writers and speakers are creating their own norms regarding spelling and what constitutes language. Therefore, for linguists and language policy makers and planners, there is need to shift away from prescriptive approaches to observed practice orientated harmonisation of writing systems, through which if examples given in this paper are anything to go by, we are likely to have much fewer and much more simplified orthographies than the ones currently in place.

Felix Banda is a professor in the Department of Linguistics at the University of the Western Cape, where he teaches undergraduate and postgraduate courses in multilingualism in society and education and technology-mediated business communication and intercultural communication. His research interests include the discursive construction of identities in society and education; the semiotics of corporate identity branding and advertising, youth and hip hop cultures and linguistic landscapes, and the educational implications of the morpho-phonology of African languages for transnational/Pan African orthography reform and design. 


\section{References}

Ashton, E. O. (1944). Swahili grammar. Harlow: Longman.

Banda, F. (2002). Towards a Bantu orthography. In K. K. Prah (Ed.), Writing African (pp. 43-54). Cape Town: Casas.

Banda, F. (2008). Orthography design and harmonisation in development in Southern Africa. Open Space, 2(3), 39-48.

Banda, F. (2009). Critical perspectives on language planning and policy in Africa: Accounting for the notion of multilingualism. Stellenbosch Papers in Linguistics PLUS, 38(2009), 1-11.

Banda, F. (2010). Defying monolingual education: Alternative bilingual discourse practices in selected coloured schools in Cape Town. Journal of Multilingual and Multicultural Development, 13(3), 221- 235.

Banda, F., \& Bellonojengele, B. (2010). Style, repertoire and identities in Zambian urban multilingual discourses. Journal of Multicultural Discourses, 5(2), 107-119.

Banda, F., Mtenje, A., Kamwendo, G., Miti, L., Ngunga, A., Liphola, M., et al. (2008). A unified standard orthography of south-central African languages: Malawi, Zambia, Mozambique. Cape Town: Casas.

Chanda, V. M. (2002). Orthography planning across languages and countries. In F. Banda (Ed.), Language across borders (pp. 27-50). Cape Town: Casas.

Chisanga, T. (2004). Lusaka Cinyanja and Icibemba: Observations on differences and similarities in some linguistic terms. In K. K. Prah (Ed.), Speaking in unison (pp. 103-116). Cape Town: Casas.

Cooper, R. (1996). Language planning and social change. Cambridge: Cambridge University Press.

Coulmas, F. (2005). Sociolinguistics: The study of speakers' choices. Cambridge: Cambridge University Press.

De Schutter, H. (2007). Language policy and political philosophy: On the emerging linguistic justice debate. Language Problems and Language Planning, 31(1), 1-23.

Djite, P. (1990). The place of African languages in the revival of the Francophonie Movement. International Journal of the Sociology of Language, 86, 87-102.

Fredericks, N. (2014). A study of dialectal and inter-linguistic variations of Khoekhoegowab: Towards the determination of the standard language. Unpublished Ph.D. Thesis, Linguistics Department, University of the Western Cape.

Gough, D. (1994). Myths of multilingualism: Democracy and democracy. Bua, 9(3), 9-11.

Greenberg, J. (1966). The languages of Africa. Bloomington: Indiana University Press.

Guthrie, M. (1967). The classification of the Bantu languages. London: Dawson of Pall Mall.

Heller, M. (2007). Bilingualism as ideology and practice. In M. Heller (Ed.), Bilingualism: A social approach (pp. 1-22). Basingstoke: Palgrave Macmillan.

Higgins, C. (2009). English as a local language. Clevedon: Multilingual Matters.

Jokweni, M. (2003). Two Nguni languages: A comparative analysis of orthography and terminology. In A. Chebanne, M. Jokweni, M. I. Mokitimi, \& S. Ngubane (Eds.), Unifying southern African languages (pp. 163-172). Cape Town: Casas.

Kashoki, M. (2009). Keeping in step with modern times: A comprehensive account of lexical adoptives in Icibemba. Cape Town: Casas. 
Lutz, M., \& Kula, N. C. (2008). One Zambia, one nation, many languages. In A. Simpson (Ed.), Language and national identity in Africa (pp. 291-313). Oxford: OUP.

Machobane, M., \& Mokitimi, M. (1998). Problems in the development of Sesotho orthography. In K. K. Prah (Ed.), Between distinction and extinction: The harmonisation and standardisation of African languages (pp. 203-212). Cape Town: Casas.

Makoni, S. (1998a). African languages as European scripts: The shaping of communal memory. In S. Nuttall \& C. Coetzee (Eds.), Negotiating the past: The making of memory in South Africa (pp. 242-249). Cape Town: Oxford University Press.

Makoni, S. (1998b). In the beginning was the missionary's word: The European invention of African languages. In K. K. Prah (Ed.), Between distinction and extinction: The harmonisation and standardisation of African languages (pp. 157-165). Cape Town: Casas.

Makoni, S., \& Mashiri, P. (2007). Critical historiography: Does language planning in Africa need a construct of language as part of its theoretical apparatus? In S. Makoni \& A. Pennycook (Eds.), Disinventing and Reconstituting languages (pp. 62-89). Clevedon: Multilingual Matters Ltd.

Makoni, S., Makoni, B., \& Rosenberg, A. (2010). The wordy worlds of popular music in Eastern and Southern Africa: Possible implications for language-in-education policy. Journal of Language, Identity, and Education, 9(1), 1-10.

Matlosa, L., Machobane, M., \& Mokatimi, M. (2003). Harmonisation of orthography of the Sotho group of languages. In C. Andy, J. Mbulelo, M. M. Isabella, \& N. Sihawukele (Eds.), Unifying southern African languages (pp. 135-142). Cape Town: Casas.

Mc Laughlin, F. (Ed.). (2009). Languages of urban Africa. London: Bloomsbury Publishing PLC.

Ministry of Education [MoE]. (1977). Zambian languages. Lusaka: National Educational Company of Zambia.

Miti, L. M. (2006). Comparative Bantu phonology and morphology. Cape Town: Casas.

Msimang, T. (1998). The nature and history of harmonisation of South African languages.

In K. K. Prah (Ed.), Between distinction and extinction (pp. 165-172). Johannesburg: University of Witwatersrand Press.

Nankindu, P. (2013). A report on the workshop for teachers on the CASAS monograph series 68 on the harmonisation of orthographic conventions of the Eastern interlacustrine Bantu languages: Luganda,

Lumasaaba, Lusaamya and Lusoga. Kyambogo University, Department of Language and Communication, 14 February 2013.

Ndhlovu, F. (2013). Cross-border languages in Southern African economic and political integration. African Studies, 72(1), 19-40.

NEEDU. (2012). The state of literacy teaching and learning in the foundation phase. Pretoria: Ministry of Education.

Pennycook, A. (2010). Language as a local practice. London: Routledge.

Prah, K. K. (1998). Introduction: The missing link in African education and development. In K. K. Prah (Ed.), Between distinction and extinction: The harmonisation and standardization of African languages (pp. 1-16). Johannesburg: Witwatersrand University Press. 
Stroud, C. (2007). Bilingualism: Colonialism and post colonialism. In M. Heller (Ed.), Bilingualism: A social approach (pp. 25-49). New York: Palgrave Macmillan.

Wakumelo-Nkolola, M., Mbala, R., Haingura, P., Makumbi, B., Muganda, R., Nairenge, K., et al. (2008). A unified standard orthography for Namibian Bantu languages. Cape Town: Casas.

Wardhaugh, R. (2006). An introduction to sociolinguistics. Malden, MA: Blackwell Publishing.

Weber, J. J., \& Horner, K. (2012). Introducing multilingualism. A social approach. Oxon: Routledge.

Zambian Government. (2012). Ubulondoloshi bwa anguka ubwa lupapulo lwakubalilapo ulushilapwa (Draft Zambian Constitution). Lusaka: Global Link.

Zerbian, S., \& Krifka, M. (2008). Quantification across Bantu languages. In L. Matthewson (Ed.), Quantification: A cross-linguistic perspective (Vol. 64, pp. 383414). North Holland Linguistic Series: Linguistic Variations.

Ziervogel, D., Lombard, D. P., \& Mokgokong, P. C. (1969). A handbook of the Northern Sotho language. Van Schaik: Pretoria. 